Tom Kai Ming Wang, MBCHB, MD

Heart, Vascular, and Thoracic Institute, Cleveland Clinic
W.H. Wilson Tang, MD

Heart, Vascular, and Thoracic Institute, Cleveland Clinic
Scott D. Flamm, MD, MBA

Heart, Vascular, and Thoracic Institute,

Cleveland Clinic
Brian Griffin, MD

Heart, Vascular, and Thoracic

Institute, Cleveland Clinic
Siddharth Dugar, MD

Respiratory Institute, Cleveland Clinic
Richard A. Grimm, DO

Heart, Vascular, and Thoracic Institute, Cleveland Clinic
Deborah H. Kwon, MD

Heart, Vascular, and Thoracic Institute, Cleveland Clinic

\title{
The role of cardiac imaging in hospitalized COVID-19-positive patients
}

\section{Posted May 1, 2020}

\begin{abstract}
COVID-19 infection is associated with several cardiac complications with high rates of adverse outcomes. Cardiac imaging has different utility in different clinical scenarios, and the importance of minimizing healthcare worker exposure should be considered. Cardiac imaging should only be ordered if its benefits outweigh its risks, with anticipated changes in acute treatment and outcomes, and no suitable alternative of sufficient adequacy is available. Indications for advanced cardiac imaging for COVID-19 patients in the acute phase are limited, although follow-up imaging in the convalescent stage may provide prognostic importance in recovered COVID-19 patients with positive troponin or decompensated heart failure.
\end{abstract}

\section{INTRODUCTION}

Since the initial cases in Wuhan, China in December 2019, coronavirus disease 2019 (COVID-19), caused by severe acute respiratory syndrome coronavirus 2 (SARS-CoV-2 or 2019-nCoV), has rapidly become a global pandemic that has overwhelmed health systems, resulting in significant mortality. ${ }^{1}$ Although COVID19 primarily affects the lungs, a global inflammatory response involving multiple organs portends a poor prognosis. ${ }^{2,3}$ Cardiovascular complications of COVID19 include acute myocardial injury in $12 \%$ to $28 \%$, arrhythmias in $7 \%$ to $17 \%$, and heart failure in about $20 \%$, although whether they were caused by or exacerbated by COVID-19 remains unclear. Nevertheless, patients with a history of cardiovascular disease are at particularly high risk of adverse outcomes. ${ }^{3-5}$

Previously, the decision to order cardiac imaging

The statements and opinions expressed in COVID-19 Curbside Consults are based on experience and the available literature as of the date posted. While we try to regularly update this content, any offered recommendations cannot be substituted for the clinical judgment of clinicians caring for individual patients.

doi:10.3949/ccjm.87a.ccc020 focused solely on balancing risks vs benefits at the patient level; however, the SARS-CoV-2 pandemic has resulted in an unprecedented impact on healthcare delivery. Clinicians now must also consider the impact of potential exposure of healthcare workers, the concern for medical devices acting as fomites and causing nosocomial spread, and the feasibility of treatment options when determining diagnostic strategies for COVID-19 patients. ${ }^{6,7}$

\section{GENERAL RECOMMENDATIONS}

It is critically important to provide basic cardiorespiratory support to COVID-19 patients based on physical assessment with a thorough evaluation of risks and benefits before considering additional testing. Therefore, the following questions should be considered when ordering cardiac imaging:

1. What is the specific clinical concern, and will the findings result in a substantial acute change in management?

2. Will the benefits of cardiac imaging outweigh the risk of potential exposure of healthcare workers and nosocomial spread of virus?

3. Are there alternative lower-risk options with sufficient accuracy to answer the clinical question?

4. Can cardiac imaging be deferred until infectious risks have been mitigated or excluded?

Cardiac point-of-care ultrasonography (cPOCUS) should preferentially be performed in COVID19 patients in the emergency room and intensive care unit by trained users when indicated. When there is uncertainty regarding the imaging findings, cPOCUS images should be reviewed with a certified cardiologist. Images should be reviewed in conjunction with any past echocardiograms and recent chest computed tomography (CT) scans (for delineation of the presence of pericardial effusion, coronary artery calcification, and cardiac chamber sizes) to determine acute findings and 
need for focused/limited echocardiography.

Transthoracic echocardiography (TTE) examination protocols should be limited to decrease exposure time, but thorough enough to answer the clinical questions at hand and prevent need for repeat studies. ${ }^{6}$

Advanced imaging techniques such as transesophageal echocardiography (TEE), cardiac computed tomography (CCT), or cardiac magnetic resonance imaging (CMR) have limited utility in the acute infectious phase for most hospitalized and acutely ill COVID-19 patients, since these are not likely to result in significant changes in acute management. TEE carries a high aerosolization risk from patients gagging or coughing, and should be avoided unless absolutely critical for diagnosis. TTE with off-axis views, use of contrast agents, or CCT with contrast for left atrial appendage thrombus assessment may occasionally serve as adequate alternatives. ${ }^{6,7}$

Infection-control precautions related to cardiac imaging should be followed with regard to equipment, personnel, protection, and location, which are outside the scope of this article. ${ }^{6,7}$

Cardiac imaging should be delayed until outpatient follow-up of COVID-19 patients with suspected subacute clinical myocardial involvement. However, given the uncertainty regarding the duration of viral shedding, the development of strategic work-flow for outpatient cardiac imaging in convalescent COVID19 patients should be considered and developed.

This commentary provides general recommendations for cardiac imaging by outlining 4 important clinical scenarios where cardiac imaging may be useful or controversial in hospitalized COVID-19 patients (Table 1).

\section{ACUTE MYOCARDIAL INJURY}

Acute myocardial injury is defined as a rise in cardiac troponins above a patient's baseline and the assay's 99th percentile upper reference level. ${ }^{8}$ The main pathophysiological processes include myocarditis, takotsubo cardiomyopathy, microvascular obstruction, capillaritis, primary coronary event of a type 1 myocardial infarction, supply-demand imbalance injury of type 2 myocardial infarction, or right ventricular strain due to right heart failure, acute respiratory distress syndrome (ARDS) or pulmonary embolism. ${ }^{8}$ Limited TTE or cPOCUS focusing on left and right ventricular dysfunction and the pattern of wall motion abnormalities may provide insight regarding the etiology and severity of acute myocardial injury, and can dictate clinical management in most circumstances. $^{9}$
Case description. A middle-aged woman was admitted to the intensive care unit for COVID-19 pneumonia. cPOCUS was performed in setting of worsening shock and markedly elevated troponin. The patient was started on intravenous heparin for deep vein thrombosis and placed in the prone position due to respiratory failure, with improvement in hemodynamics and respiratory status. After 5 days she again become hypotensive, and cPOCUS showed normal left ventricular and right ventricular function with a collapsible inferior vena cava responding to a gentle fluid bolus.

Because CMR is the most comprehensive imaging modality to elucidate underlying pathophysiology, some guidelines have recommended inpatient CMR for treatment disposition. ${ }^{7}$ However, increased risk of exposure of healthcare workers should strongly be considered, and CMR should be deferred in the acute setting if management by echocardiographic assessment is sufficient for acute therapeutic guidance. Alternatively, CMR during the convalescent phase may elucidate important mechanistic insights regarding the pathophysiology and extent of myocardial injury, which can dictate therapeutic strategies and determine the likelihood of left and right ventricular recovery vs conversion into chronic heart disease. ${ }^{9}$

\section{ACUTE CHEST PAIN WITH OR WITHOUT ELECTROCARDIOGRAPHIC CHANGES}

For COVID-19 patients with acute coronary syndromes, cPOCUS/focused TTE can determine important diagnostic and prognostic features. Because COVID-19 patients are at higher risk of venous thromboembolism including pulmonary embolism, along with right ventricular failure from ARDS, focused attention on the right ventricle should be an important component in all patients undergoing cPOCUS/ limited TTE. ${ }^{10}$ Patients with preserved cardiac function with no high-risk features of heart failure, cardiogenic shock, dynamic electrocardiographic changes, or medically refractory symptoms should be managed conservatively. Patients with stable symptoms and low or intermediate risk should have imaging deferred to a later date and be treated medically unless their condition becomes progressive and clinically unstable. ${ }^{6,7}$

Invasive coronary angiography and revascularization should be considered only in the scenario of ST-elevation myocardial infarction; however, thrombolysis is a reasonable alternative in SARS-CoV-2 infection. If invasive coronary angiography is warranted, then left ventriculography may eliminate the need for $\mathrm{TTE}^{6}$ in the acute setting. 
TABLE 1

Suggested cardiac imaging tests by cardiovascular scenarios for hospitalized COVID-19 patients

\begin{tabular}{|c|c|c|c|c|}
\hline \multicolumn{5}{|c|}{$\begin{array}{l}\text { Key questions before ordering imaging for 'acute phase' } \\
\text { 1) What is the clinical concern, and will the findings result in substantial acute change in management? } \\
\text { 2) Will the benefits of cardiac imaging outweigh the risk of potential exposure healthcare workers and nosocomial spread of virus? } \\
\text { 3) Are there alternative, lower-risk options with sufficient accuracy? } \\
\text { 4) Can cardiac imaging be deferred until infectious risks have been mitigated? }\end{array}$} \\
\hline & $\begin{array}{l}\text { Acute myocardial } \\
\text { injury }\end{array}$ & $\begin{array}{l}\text { Chest pain with or without } \\
\text { electrocardiographic } \\
\text { changes }\end{array}$ & $\begin{array}{l}\text { Decompensated heart failure } \\
\text { or acute hypoxia }\end{array}$ & Suspected infective endocarditis \\
\hline $\begin{array}{l}\text { Clinical and } \\
\text { biomarker data } \\
\text { to guide the } \\
\text { need for acute } \\
\text { cardiac } \\
\text { imaging }\end{array}$ & $\begin{array}{l}\text { Pattern of troponin } \\
\text { elevation and severity } \\
\text { of acute lung injury } \\
\text { pattern }\end{array}$ & $\begin{array}{l}\text { Risk stratification of } \\
\text { coronary heart disease, } \\
\text { troponin criteria }\end{array}$ & $\begin{array}{l}\text { Established cardiovascular } \\
\text { disease, symptoms and signs } \\
\text { of heart failure, NT-proBNP } \\
\text { and troponin levels }\end{array}$ & $\begin{array}{l}\text { Risk stratification, bacteremia } \\
\text { organism, need for surgery }\end{array}$ \\
\hline $\begin{array}{l}\text { Determinants } \\
\text { for cardiac } \\
\text { imaging: } \\
\text { 'acute phase' }\end{array}$ & $\begin{array}{l}\text { Location of patient } \\
\text { Emergency } \\
\text { department or } \\
\text { intensive care unit: } \\
\text { cPOCUS } \\
\text { Regular nursing floor: } \\
\text { TTE (if cPOCUS } \\
\text { unavailable) }\end{array}$ & $\begin{array}{l}\text { STEMI: Urgent invasive } \\
\text { coronary angiography } \\
\text { (defer TTE), thrombolysis } \\
\text { (do TTE) } \\
\text { Other acute coronary } \\
\text { syndromes or high risk: } \\
\text { TTE/cPOCUS } \\
\text { Submassive pulmonary } \\
\text { embolism on CTA: Assess } \\
\text { right ventricle by } \\
\text { TTE/cPOCUS }\end{array}$ & $\begin{array}{l}\text { Medically refractory } \\
\text { cardiogenic shock: } \\
\text { TTE/cPOCUS, CCT for } \\
\text { refractory atrial fibrillation } \\
\text { requiring direct current } \\
\text { cardioversion, invasive } \\
\text { coronary angiography for } \\
\text { patients with high suspicion of } \\
\text { severe coronary artery disease } \\
\text { Submassive pulmonary } \\
\text { embolism on CTA: Assess } \\
\text { right ventricle by } \\
\text { TTE/cPOCUS } \\
\end{array}$ & $\begin{array}{l}\text { Discuss with infectious disease } \\
\text { specialist if imaging would change } \\
\text { treatment (if yes, TTE; if no, defer } \\
\text { imaging) } \\
\text { TTE positive: consult infectious } \\
\text { disease service to determine need } \\
\text { for further imaging }\end{array}$ \\
\hline \multicolumn{5}{|c|}{$\begin{array}{l}\text { Patients with cardiovascular complications of COVID-19 should return for outpatient follow-up 4-6 weeks. Strategies for determining } \\
\text { the need for PPE/repeat testing in the convalescent phase are to be determined. }\end{array}$} \\
\hline $\begin{array}{l}\text { Cardiac } \\
\text { imaging: } \\
\text { 'convalescence } \\
\text { phase' follow- } \\
\text { up }\end{array}$ & $\begin{array}{l}\text { Intermediate risk: } \\
\text { Stress TTE, NUC, } \\
\text { CMR } \\
\text { Low risk: TTE } \pm \text { CMR }\end{array}$ & $\begin{array}{l}\text { STEMI follow-up: TTE } \\
\text { Intermediate risk: Stress } \\
\text { TTE, NUC, CMR or CCT } \\
\text { Low risk: TTE } \pm \text { CMR }\end{array}$ & $\begin{array}{l}\text { TTE } \pm \text { CMR } \\
\text { Consider coronary CTA for } \\
\text { patients with intermediate-low } \\
\text { likelihood of severe coronary } \\
\text { artery disease }\end{array}$ & $\begin{array}{l}\text { Clinical deterioration: TTE } \pm \text { TEE } \\
\text { Clinically well: Follow-up with } \\
\text { infectious disease specialist and } \\
\text { cardiologist to determine need for } \\
\text { follow-up imaging }\end{array}$ \\
\hline
\end{tabular}

$\mathrm{CCT}=$ cardiac computed tomography, CMR = cardiac magnetic resonance imaging, $\mathrm{CPOCUS}=$ cardiac point-of-care ultrasonography, CTA = computed tomographic angiography, $\mathrm{NUC}=$ nuclear imaging, NT-proBNP $=\mathrm{N}$-terminal pro-B-type natriuretic peptide, STEMI $=$ ST-elevation myocardial infarction, TTE $=$ transthoracic echocardiography.

\section{DECOMPENSATED HEART FAILURE}

Discerning decompensated heart failure may be challenging in COVID-19 patients because the primary manifestation of severe COVID-19, ARDS, can mimic cardiogenic pulmonary edema. cPOCUS/TTE should be performed in decompensated heart failure patients with no prior history of heart failure, clinical signs of decompensated heart failure, or evidence of hemodynamic instability. ${ }^{6,9}$ However, cardiac imaging should be deferred in COVID-19 patients with known history of heart failure or cardiomyopathy who are otherwise hemodynamically stable.

Other imaging modalities do not have a role in acutely ill COVID-19 patients with acute decompensated heart failure, apart from those with atrial fibrillation, when decompensated heart failure cannot be adequately managed without restoring normal sinus rhythm. CCT with contrast can be used as an alternative to TEE to assess the left atrial appendage prior to cardioversion. ${ }^{7} \mathrm{CMR}$ should be deferred until patients are clinically stable, and can be performed during the convalescent stage. ${ }^{?}$

\section{SUSPECTED INFECTIVE ENDOCARDITIS}

Infective endocarditis shares common presentations with COVID-19 including fever, sepsis, and fatigue. However there are no cases in the literature currently reporting concomitant infective endocarditis with SARS-CoV-2 infection. The need for any cardiac imaging for suspected infective endocarditis in COVID-19 patients should be discussed with infectious disease services to consider the likelihood for change in management beyond extended intravenous antibiotic therapy.

TTE remains the first-line modality, and no further investigations are required if it is negative with adequate views. Clinicians should consult an infectious disease specialist regarding the need for further imaging in 
higher-risk patients with typical bacteremia organisms such as Staphylococcus aureus, viridans streptococci, or Enterococcus, and new valvular lesions on TTE. Further imaging should only be performed to discern the need for surgical intervention in appropriate patients. ${ }^{6,7}$

\section{CONCLUSION}

COVID-19 infection is associated with several cardiac complications with high rates of adverse outcomes. Cardiac imaging has different utility in different clinical scenarios, and the importance of minimizing health care worker exposure should be considered. Cardiac imaging should only be ordered if its benefits outweigh its risks, with anticipated changes in acute treatment and outcomes, and no suitable alternative of sufficient adequacy is available. Indications for advanced cardiac imaging for COVID-19 patients in the acute phase are limited, although follow-up imaging in the convalescent stage may provide prognostic importance in recovered COVID-19 patients with positive troponin or decompensated heart failure.

\section{REFERENCES}

1. Zhou P, Yang $\mathbf{X L}$, Wang $\mathbf{X G}$, et al. A pneumonia outbreak associated with a new coronavirus of probable bat origin. Nature 2020; 579(7798):270-273. doi:10.1038/s41586-020-2012-7

2. Guan WJ, Ni ZY, Hu Y, et al. Clinical characteristics of coronavirus disease 2019 in China. N Engl J Med 2020 Feb 28;NEJMoa2002032. doi:10.1056/NEJMoa2002032
3. Zhou F, Yu T, Du R, et al. Clinical course and risk factors for mortality of adult inpatients with COVID-19 in Wuhan, China: a retrospective cohort study. Lancet 2020; 395(10229):1054-1062. doi:10.1016/ S0140-6736(20)30566-3

4. Guo T, Fan Y, Chen M, et al. Cardiovascular implications of fatal outcomes of patients with coronavirus disease 2019 (COVID-19). JAMA Cardiol 2020 Mar 27;e201017. doi:10.1001/jamacardio.2020.1017

5. Huang C, Wang Y, Li X, et al. Clinical features of patients infected with 2019 novel coronavirus in Wuhan, China. Lancet 2020; 395(10223):497-506. doi:10.1016/S0140-6736(20)30183-5

6. Kirkpatrick JN, Mitchell C,Taub C, Kort S, Hung J, Swaminathan M. ASE Statement on protection of patients and echocardiography service providers during the 2019 novel coronavirus outbreak: J Am Coll Cardiol 2020 Apr 6;S0735-1097(20)34815-4. doi:10.1016/j. jacc.2020.04.002

7. Skulstad H, Cosyns B, Popescu BA, et al. COVID-19 pandemic and cardiac imaging: EACVI recommendations on precautions, indications, prioritization, and protection for patients and healthcare personnel. Eur Heart J Cardiovasc Imaging 20202020 Apr 3;jeaa072. doi:10.1093/ehjci/jeaa072

8. hygesen K, Alpert JS, Jaffe AS, et al. Fourth universal definition of myocardial infarction (2018). J Am Coll Cardiol 2018; 72(18):22312264. doi:10.1016/j.jacc.2018.08.1038

9. Doherty JU, Kort S, Mehran R, et al. ACC/AATS/AHA/ASE/ASNC/HRS/ SCAI/SCCT/SCMR/STS 2019 Appropriate use criteria for multimodality imaging in the assessment of cardiac structure and function in nonvalvular heart disease: a report of the American College of Cardiology Appropriate Use Criteria Task Force, American Association for Thoracic Surgery, American Heart Association, American Society of Echocardiography, American Society of Nuclear Cardiology, Heart Rhythm Society, Society for Cardiovascular Angiography and Interventions, Society of Cardiovascular Computed Tomography, Society for Cardiovascular Magnetic Resonance, and the Society of Thoracic Surgeons. J Am Coll Cardiol 2019; 73(4):488-516. doi:10.1016/j.jacc.2018.10.038

10. Repessé $X$, Charron C, Vieillard-Baron A. Right ventricular failure in acute lung injury and acute respiratory distress syndrome. Minerva Anesthesiol 2012; 78(8):941-948. PMID:22672932 